\title{
Vigencia del pensamiento de Monseñor Sanabria para una teología y política solidaria e inclusiva global ${ }^{*}$
}

\author{
José Francisco Rosales Blandino**
}

Recibido: Julio 2011 • Aceptado: Setiembre 2011

RESUMEN

El presente ensayo se propone confrontar los aportes más característicos del pensamiento y acción pastoral de Mons. Sanabria en el marco de la Iglesia costarricense, preocupada por los graves problemas del hombre y de la sociedad actual. Democracia con justicia solidaria e inclusividad social son pilares de su pensamiento y fermento de toda actual y futura renovación teológica y política.

Palabras clave: Pensamiento de Mons. Sanabria, Iglesia costarricense, Democracia, Justicia, Solidaridad, Inclusividad, Política solidaria.

\begin{abstract}
The next essay proposes to face the most characteristic contribution of the thought and pastoral action of Mgr Sanabria in the Costa Rican church framework, worried about the grave problems of man and the current society. Democracy with solidarity justice and social inclusion are the pillars of the thought and ferment of the whole present and future theological and political renovation.
\end{abstract}

Key words: Pensamiento de Mons. Sanabria, Iglesia costarricense, Democracia, Justicia, Solidaridad, Inclusividad, Política solidaria.

* Arzobispo de San José de Costa Rica (1940-1952). Benemérito de la Patria (1959). Padre de la historiografía eclesiástica costarricense y de los estudios genealógicos nacionales.

** Teólogo costarricense. Bachiller en Filosofía por la Universidad Católica Anselmo Llorente y Lafuente (1994), Licenciado en Teología por la Universidad Gregoriana (Roma 1996), Doctorado por la Universidad Santo Tomás (Angelicum. Roma 2004). Docente en Teología y Filosofía en la Universidad Nacional, Universidad de Costa Rica, Universidad Anselmo Llorente, Universidad Estatal a Distancia e Instituto Teológico de América Central. 


\section{Preámbulo}

La connotación universal del pensamiento y obra de Monseñor Sanabria ha sido el objeto de mi disertación doctoral y su propósito fue alcanzado (Rosales 2009). La universalidad de Sanabria adquiere especial relevancia al constatarse que su visión pastoral implicó no solo la elaboración de una innovadora perspectiva teológica sino también un verdadero y eficaz encuentro resolutivo con la problemática social de su tiempo. Sus acertadas implicaciones perduran hasta nuestros días en la figura, entre otras secuelas, del estado social de derecho costarricense.

Para el presente ensayo, me propongo confrontar los aportes más característicos del pensamiento de Sanabria, vertidos en su acción pastoral, con la temática común de la presente colaboración sobre el futuro de Dios y del hombre en la sociedad global. Esta confrontación se propone enmarcarse dentro de la posibilidad de una teología y política solidaria e inclusiva global inspiradas en la visión de nuestro autor.

\section{Aportes característicos de Sanabria}

Se puede afirmar que los aportes de Sanabria atinentes al orden social y político de su tiempo estuvieron fuertemente influenciados por la propuesta filosófico-teológica del pensador francés Jacques Mari$\operatorname{tain}^{1}$. Este dejó un profunda huella e inspiración en las jóvenes generaciones de la primera parte del siglo XX y en especial en América Latina en donde aportó una opción humanista integral al insoluble dilema entre izquierdas comunistas y derechas facistas que originaron las condiciones para el dramático y desgastante conflicto entre dictaduras y guerrillas que desangraron generaciones de jóvenes promesas en nuestro subcontinente. ${ }^{2}$

1. "Para mí los escritos de Maritain fueron una revelación de las grandes posibilidades de la filosofía escolástica, posibilidades que sin duda alguna, debido a mi escaso talento, no había llegado a vislumbrar con tanta claridad durante el tiempo de mis estudios filosóficos. No hay en verdad sistema filosófico más sólido ni más dúctil ni más moderno, a pesar de sus años, que el escolástico. Aprendí por consiguiente, que en la Escolástica había tenido siempre a mano, el suscrito, un arma poderosa, y que había que aprender a usarla siempre que fuera necesario, en la defensa de los principios cristianos y en el análisis de tantas cuestiones que se rozan directa o indirectamente con los problemas del día”. (AE SANABRIA $56(\mathrm{CH}) 30$ )

2. En marzo de 1948 Alceu Amoroso Lima, filósofo brasileño converso, escribió para una edición especial de la Revue Thomiste, dedicado a Jacques Maritain, "la renovación tomista en América, como también la solución cristiana de los problemas sociales del Nuevo Mundo deben a Jacques Maritain más que a cualquier otro pensador moderno el mejor impulso de su fuerza actual. Esto basta para mostrar la extensión de su irradiación intelectual" (AAVV 1948: 17). 
A partir de este presupuesto procedo a presentar en dos secciones los aportes de Sanabria en la perspectiva filosófico-social y en la teológica-pastoral, respectivamente, para posteriormente realizar una confrontación con el panorama presente y futuro de nuestra sociedad global. Con ello se contará con los fundamentos para visualizar una propuesta de una teología y política solidaria e inclusiva global a partir del aporte del benemérito pastor costarricense.

\footnotetext{
"El mismo que nos había revelado la profunda compatibilidad entre la inteligencia humana y la verdad, venía entonces a revelarnos la adecuación natural entre la libertad y el bien común. Nosotros habíamos confundido libertad y liberalismo, autoridad y dictadura. Maritain, a la luz de los principios más puros del derecho natural y de la filosofía tradicional, venía a mostrarnos cómo hacía falta distinguir para unir. $\mathrm{Su}$ enseñanza que nos había sacado del escepticismo o del irracionalismo hacia un intelectualismo ordenado o real integral, venía entonces, sobre el plano político, a sacarnos de opciones unilaterales hacia una síntesis total donde la libertad y la autoridad se integraban naturalmente dentro de la verdad. Todo ello se tradujo concretamente en el rechazo del comunismo y del facismo y en la rehabilitación de la democracia basada sobre los principios de la sabiduría cristiana. Los problemas políticos tenían entonces en América una repercusión que faltó a los problemas filosóficos. Mientras la influencia de Maritain se ejerció solamente sobre el plano religioso y metafísico, todo el mundo lo aceptó sin reserva. Desde el momento que tocó los problemas políticos y sobre todo después de los acontecimientos de España, todo cambió". (AAVV 1948: 15)
}

Con el fin de esbozar con la mayor claridad y utilidad el desarrollo de nuestra temática opto por hacerlo desde la selección de los tres principales aspectos en cada campo temático arriba propuestos.

\section{Aportes filosófico-sociales de Sanabria}

\section{Sanabria aporta una visión desde la perspectiva histórica}

Sanabria llegó a ser historiador más por vocación que por profesión. Sus estudios en Roma lo pusieron en contacto con maestros como Wernz quienes con sus tratados de derecho pusieron en contacto al joven Sanabria con la metodología histórico-crítica alemana en la canonística. ${ }^{3} \mathrm{Si}$ a ello sumamos el innato y devoto sentido de amor patrio de nuestro pastor, se puede explicar con sobrada razón la pasión con que él se entregó a la indagación histórica dedicando largas horas a la visita de los archivos eclesiásticos sin escatimar

3. Características del método teológico entonces empleado lo fueron la exégesis dogmática en el sentido de la escolástica enriquecida con el empleo de los resultados de las ciencias filológicas e históricas no contentándose con presentar la interpretación de los textos escriturísticos dada por los grandes escolásticos sino esforzándose por descubrir el sentido de la Escritura "en el contexto de la tradición patrística y escolástica". (ANTÓN II 1987: 430) 
el robarle tiempo al sueño. $\mathrm{Ni}$ la sobrecarga pastoral que tuvo de presbítero ni las graves responsabilidades y conflictos sociales que rodearon su ministerio episcopal impidieron que hasta el último año de su vida perseverara en su hábito investigativo.

Desde esta característica de su inquietud intelectual resulta natural que Sanabria llame a la historia "crisol de justicia" (ENSA 622). En su magisterio epistolar y pastoral se puede constatar el peso que la perspectiva histórica jugó para interpretar y dilucidar las decisiones más oportunas ante las más graves situaciones que le correspondió afrontar.

A esta inclinación se suma su profunda adhesión a la obra de Jacques Maritain quien supo conjugar la rigurosidad del tomismo con la dimensión histórica del desarrollo cultural. Es de Maritain el interpretar la realidad desde los diversos "climas históricos" para formular los diversos "proyectos históricos" pertinentes en vez de acudir al uso de la ambivalente noción de "utopía" tan en boga en su época (AA VV 1982).

Dicho lo anterior, cabe afirmar que el primer aporte de Sanabria vigente para una propuesta de sociedad global solidaria es contar con la memoria histórica glocal como se acostumbra llamar (global y local).
Ningún proyecto de sociedad será viable ni sostenible sin partir ni contar con una historia común. La historia nos desnuda y puede hacer sentir vulnerables a nuestras faltas pasadas pero a la vez dignifica nuestras posibilidades reales de futuro. El ignorar la historia "maestra de vida" (Juan XXIII) es invisibilizar a los responsables de nuestra fortuna y miseria actual acallando la resolución de las causas que nos han impedido alcanzar mayores grados de solidaridad y sociedad.

Valga agregar que para Sanabria la indagación histórica fue un espacio privilegiado de encuentro y convergencia decisivo para el diálogo y colaboración tanto con personas como con líderes políticos no confesionalmente cristianos como Cleto González Víquez y Manuel Mora Valverde, de posiciones ideológicas y políticas diametralmente opuestas.

\section{Sanabria aporta desde una visión ética}

Aunque parezca sobradamente obvio por su investidura pastoral, es de puntualizar que Sanabria ofrece la verificación de la centralidad de la cuestión ética en la consideración y resolución de toda problemática humana y social. Tanto su prioridad pastoral por formar "la conciencia cristiana" de los fieles como el respetar y contar con la 
conciencia humana en general forman parte de la fórmula que hizo posible el consenso social para la superación de los desafíos de su tiempo ${ }^{4}$ (ENSA 185).

Con lo arriba dicho se puede afirmar que para Sanabria la cuestión ética no implicó una postura sectaria de cara al resto de la humanidad. Todo lo contrario, fiel a Maritain, él supo comprender y aplicar la valoración de que la ética

4. Considérese su gran presupuesto antropológico: "Católicos y no católicos han afirmado que la vida del hombre, desde que nace hasta que muere, es un continuado hecho teológico. Implícitamente hallamos este concepto en el discurso pronunciado por San Pablo en el Areópago de Atenas, en el que dijo de Jesucristo, y por consiguiente de su doctrina, que "dentro de Él vivimos, nos movemos y somos" [Hch 17, 28]. Y no podía ser de otra manera. El hombre, como criatura espiritual, desde que nace está necesariamente en contacto con un orden trascendental, el orden sobrenatural, en el que vive, se mueve y existe. Como ser dotado de inteligencia es un vivero de ideas, todas las cuales hallan su rectificación y contraste en las esferas de la verdad, y como ser dotado de voluntad libre, es autor verdadero de acciones responsables, todas las cuales tienen un valor determinado en la balanza de la moral. Requiere, pues, criterios para el pensamiento, y criterios para la acción, o sea criterios estrictamente teológicos y criterios teológico-morales, que regulen sus relaciones con Dios, consigo mismo y con sus semejantes, como que de hecho casi no hay acciones que no sean de valor trascendental. Tal es el pensamiento de San Pablo: "Ninguno de nosotros vive para sí, y ninguno de nosotros muere para sí. Que si vivimos, para el Señor vivimos, y si morimos, para el Señor morimos... Ora pues vivamos, ora muramos, del Señor somos" [Rm 14, 7-8].” (ENSA 367) secular contemporánea no solo deriva de la inspiración cristiana sino que sigue siendo compatible con esta y dispuesta para la resolución conjunta de toda problemática humana dentro de un contexto democrático y plural. ${ }^{5}$

5. El diputado Trejos Dittel afirmaba en 1959:

"Todavía recuerdo las frases sabias de este ilustre desaparecido, una memorable tarde de un sábado, cuando nos habló a los que formábamos parte de esa Federación, sobre la necesidad de que trajináramos también por esos elevados y a veces misteriosos campos de la teología. Recuerdo perfectamente sus manifestaciones clarividentes, que nos ponían a consideración de los que, paganos en esas materias, teníamos no obstante, cierta inquietud por iniciarnos en esos senderos de luz; recuerdo sus frases que nos hacían comprender que además, todos los que profesan la fe cristiana, deben saber que hay otra sabiduría racional, que tiene sus raíces en la fe, y no sólo en la razón.

Recuerdo que nos decía que esa sabiduría es superior a toda otra simplemente humana, inclusive superior a la propia metafísica. Recuerdo que nos explicaba que de hecho, todos los problemas y las controversias teológicas han impregnado la cultura y la civilización occidental a lo largo de todo su desarrollo y siguen actuando en lo más profundo de sus entrañas. De tal suerte que quien pretendiera ignorar esos conocimientos teológicos, era absolutamente incapaz de comprender al propio tiempo, el sentido de sus propias inclinaciones o de sus internos conflictos.

Decía Monseñor Sanabria, en esa oportunidad, que privado así el hombre del elemento de cultura, sería como un niño bárbaro y desarmado que anduviera errando por entre la incomprensible mezcolanza de árboles de fuentes, de estatuas, de jardines, ruinas y edificios todavía en construcción del viejo parque de la civilización. Recuerdo que nos hablaba con sus conocimientos profundos 
Es dentro de esta posición como la noción de justicia ocupa la centralidad de su preocupación y ocupación personal y ministerial. Gracias a ello vivió un profundo y fecundo encuentro con los líderes políticos y agentes sociales de su época.

$\mathrm{Si}$ a ello se suma que para Sanabria la ética no se agota en la elucubración mental sino que implica un plan y práctica histórica verificables, resulta evidente que el lugar de la praxis en su visión constituye un aspecto esencial de su aporte desde la perspectiva ética. ${ }^{6}$

de la historia, de lo que ha significado el conocimiento teológico para la comprensión y el aprovechamiento de las enseñanzas de esas páginas de la Historia Universal. Nos decía que la historia intelectual y política de cualquier siglo que uno estudiara, cualquier fenómeno histórico que uno analizara, la Reforma, la Contrarreforma, el estado interior de los países antes y después de la Revolución Francesa, todos esos fenómenos, decía Monseñor Sanabria, analizados a la luz de la teología, daban al hombre una dimensión espiritual que de lo contrario no tendría para valorar en todos sus alcances los aconteceres de la historia de cualquier pueblo o de la misma humanidad completa" (Blanco 1971: 358). Esta es precisamente la temática que desarrolla Maritain en su primer capítulo de Humanismo Integral y que intitula La tragedia del humanismo (MARITAIN 1980: 65-88).

6. Ello se demuestra con creces en su propuesta pastoral con base en planes de acción concreta presentes en su I y IV Cartas Pastorales (ENSA 1-63 y 132-191).

En su célebre carta a Don Pedro Basaldúa concluye el obispo: "El que quiera continuar contemplando 'románticamente' las
Actualizando la vigencia del pensamiento de Sanabria para una sociedad global y solidaria, resalta el hecho de que tanto el hecho mismo de la sociedad como de la solidaridad que implica entrañan inevitablemente la centralidad de la cuestión ética. A este dato claramente evidente se debe sumar el gran presupuesto maritainiano de la compatibilidad de fondo de la ética cristiana con toda ética verdaderamente humana. Este aporte resulta más que pertinente cuando a inicios del siglo XXI se reviven posiciones fundamentalistas, integristas y anticlericalistas de todo tipo, creándose las condiciones para la exclusión solapada y expresa de significativos sectores de la sociedad en el diálogo y construcción de modelos sociales más incluyentes y solidarios.

\section{Sanabria aporta desde una opción humanista}

A pesar de que pueda resultar redundante con lo hasta aquí enunciado, la vigencia del pensamiento cuestiones sociales del día, que lo haga, pero que tenga un poco de caridad para los 'prácticos'. Importante es citar los textos de las Encíclicas Pontificias sobre materias sociales, pero también es de importancia citar como textos 'vivos' de las Encíclica (sic), las obras que por inspiración de aquellas, quieran realizar los católicos de buena voluntad". AE SANABRIA 56(CH)32 
de Sanabria para una sociedad global y solidaria conlleva necesariamente a considerar y poner de relieve su convencida y profunda opción humanista. Seguidor del humanismo integral de Maritain y enmarcado históricamente en el trágico desarrollo de la peor catástrofe bélica de la historia humana Sanabria nunca perdió de vista y más aún privilegió en todo momento la protección y el desarrollo de la condición humana universal. ${ }^{7}$

Esta opción resulta tan imprescindible hoy como lo fue en su

7. Su apreciación humanista sobre la identidad latinoamericana la confesó a un ex opositor: "Y ahora una confidencia. De las cosas que de mi perseguida humanidad se han dicho, dos me han complacido siempre. Más aún, me han envanecido. De "la color", que bien a la vista está, y a la que yo considero siempre como una "demostración democrática" de que van descarriados los que piensan con la piel. Y de la humildad de mis orígenes, poco más o menos por la misma razón. Es lo que más me ha agradado del comentario de este agudo norteamericano. Son tantos, y Ud. bien lo sabe, los que teniendo ese color y contando con esos orígenes, nada hacen, pudiéndolo hacer, por el mejoramiento de sus iguales. Hasta en esto hace sus víctimas el famoso "respeto humano" de que tantos (sic) nos hablaban en el Seminario, Ud. lo recordará, en las pláticas de los Ejercicios Espirituales. Cuanto adelantarían sus tesis, don Vicente, si estos países, que viven bajo el complejo del "rubio", llegaran a sentirse orgullosos de "la color" y de su origen que, mirado éste con ojo histórico, es la más admirable mezcla que Dios está fundiendo en éste caldero de razas que es la América Latina”. V. SANABRIA, carta a Vicente Sáenz, 11 de octubre de 1949 en AE SANABRIA $59\left(\mathrm{CH}^{\prime}\right) 27$. época. Si en su época la cuestión social y el conflicto armado caracterizaban el orden del día, hoy las posiciones economicistas, tecnocráticas y extremistas urgen la renovada opción por un humanismo decidido, consecuente y sin fronteras que, como afirmaba Juan Pablo II en Redemptor Hominis 18 (1978), se acredite más por los hechos en beneficio de la persona humana que en sus pretendidas y humanamente onerosas utopías.

\section{Aportes teológico-pastorales de Sanabria}

\section{Para Sanabria la Iglesia es parte de la solución, no toda la solución}

Clave para la debida comprensión y valoración de la eficacia con la que Sanabria colaboró con su generación en la superación del drama social de su época es la clara y expresa conciencia con la que él declaró que la Iglesia es parte de la solución no toda la solución, de los problemas sociales. ${ }^{8}$ Esta posición

8. "Somos una fuerza para la solución del problema social pero no somos toda la fuerza que para el caso se requiere. No pocas veces esa fuerza es nula porque nuestra voz es voz que clama en el desierto. Creemos que nadie podrá enrostrar de buena fe a la Iglesia, que no acuerpa con su autoridad cuantas medidas y reformas sanas imponen o impongan quienes para ello tiene el poder, los medios y la fuerza de compulsión social en el terreno político, económico y social, para resolver esta cuestión" (ENSA 175). 
inteligente tan honesta y sobria abrió las puertas para una colaboración inédita e innovadora en nuestra historia patria.

Ya desde los principios de su formulación implica una necesaria actitud inclusiva en relación con la sociedad pues esta no se reduce ni identifica con la sociedad eclesial sino que esta última es su integrante entre otros agentes y personas con las que está decidida a interactuar. De esta forma, el bien social ya no aparece rígidamente ligado a la sola actuación eclesial sino a la colaboración de todos los agentes sociales, implicando con ello necesariamente el valor de la inclusión y solidaridad en la deliberación de los mejores caminos de desarrollo y bienestar para la sociedad.

En el momento de actualizar este aporte de Sanabria en la temática que nos ocupa resulta inmediatamente evidente que para una sociedad global y solidaria la Iglesia está llamada a integrarse como parte y sumar con los demás en tantos tópicos en los que se une el destino de la humanidad, y más que en aquellos en que se divide parafraseando al Papa Bueno.
Para Sanabria el cristianismo y el humanismo secular son compatibles desde lo ético social

Como se ha indicado antes, el influjo maritainiano condujo a Sanabria a adoptar una actitud de abierto diálogo social. Para el Maritain del Humanismo Integral (1934) las corrientes secularistas de la modernidad no son otra cosa que la traducción laica de los valores espirituales del cristianismo (MARITAIN 1980: 65-88). El mismo autor cultivó en su casa un amplio y diverso intercambio con variados representantes de las tendencias culturales de entonces (SAN MARTÍN 1999: 42).

Por su parte, Sanabria practicó este diálogo con toda clase de interlocutores sociales y de manera especial con el Secretario del Partido Comunista de entonces, el Lic. Manuel Mora Valverde.

Desde este presupuesto, el aporte de Sanabria a una sociedad global y solidaria establece un principio de fundamental compatibilidad entre las aspiraciones de la humanidad y la misión de la Iglesia. Si se parte de que al menos 
un tercio de la humanidad profesa el cristianismo, las implicaciones del cultivo permanente y eficaz de un dialogo constructivo entre cristianismo y mundo debe ser un primado en la práctica y mensaje cristiano para establecer los fundamentos de dicha sociedad.

\section{Para Sanabria la democracia y el bien común son los pilares de toda sociedad verdaderamente justa}

Precisamente en la hora más álgida de la historia costarricense del siglo XX, la Revolución de 1948, la posición del Arzobispo fue apoyar la institucionalidad de las instancias democráticas y sus disposiciones. Esta postura no solamente fue compartida por los diversos colegios profesionales y la generalidad de la población de entonces, sino también por el candidato a quien se le negó en ese momento su victoria electoral, el Lic. Otilio Ulate Blanco, quien ya como presidente expresó en el novenario de la muerte de Sanabria, en junio de 1952, que si se hubiera aceptado la mediación y propuesta de éste, Costa Rica se habría ahorrado la sangre vertida ( ULATE 1952: 162-163).

El valor de la democracia en Sanabria se vio reforzado por la visión Maritainiana quien la estimó como lo característico del "clima histórico" contemporáneo. En contraste con la cristiandad medieval, Maritain señaló el pluralismo, la libertad individual, la igualdad y el progreso temporal como los rasgos distintivos del nuevo orden social. Desde esta perspectiva, Sanabria se inspiró en las implicaciones prácticas o pastorales de dicha situación propuestas por Maritain. En suma, estas implicaciones estructuraron la presencia y acción de la Iglesia desde la autonomía del laicado en tres esferas: la interna espiritual, la medianera pastoral y la estrictamente secular, acorde con la ocupación y formación de cada creyente. ${ }^{9}$ Para Sanabria y Maritain estas esferas de acción comparten tanto la misma finalidad temporal como la eterna desde los valores que las sustentan (Maritain 1980: 307ss.).

Aunque suene redundante la reafirmación del orden democrático para la consecución de la finalidad social humana, este es un presupuesto $\mathrm{y}$ valor imprescindible $\mathrm{y}$, como tal, necesitado de una defensa y promoción constantes por todos los miembros de la sociedad, y en especial por sus líderes espirituales. El siglo XX testimonió los abusos que

9. En su praxis pastoral Sanabria tradujo estas tres esferas de acción en la constitución y proyección social de tres agrupaciones: la Liga Espiritual Obrera (LEO), la Juventud Obrera Católica (JOC) y la Confederación Costarricense de Trabajadores Rerum Novarum (CCTRN), respectivamente. 
tanto los defensores de la libertad como de la igualdad cometieron en nombre de sus valores representativos. La experiencia nos ha enseñado que la democracia efectiva fue la primera víctima de dichos abusos. Así que sea cual fuere el modelo del proyecto de sociedad global futura y solidaria, su conditio sine qua non debe ser la práctica de las condiciones propias de un orden social verdaderamente democrático.

\section{Urgencias presentes y futuras de toda sociedad global}

\section{La Democracia como desafío permanente}

La democracia es parte de aquellos valores como la libertad y la justicia que han de ser cultivados, protegidos y promovidos incesantemente. Más aún cuando el régimen democrático no solo cuenta con una historia relativamente reciente en el mundo occidental sino cuando inmensas poblaciones del lejano oriente, Asia y África, están prácticamente privadas de una real participación democrática en la vida de sus naciones. ${ }^{10}$

10. De acuerdo con Transparencia Internacional para noviembre del 2009, de 150 naciones 83 gobiernos están por debajo del cuestionable estado de Honduras quien ocupa el puesto 67. Costa Rica ocupa el puesto 23 y las tres primeras democracias mundiales son Dinamarca, Suiza y Nueva
Corresponde insistir en que sea cual sea el modelo de sociedad global y solidaria que se quiera, su fundamento ha de ser necesariamente democrático. Y con ello los derechos humanos resultan esenciales en su construcción y vida.

\section{La Justicia como imperativo ético}

Más allá de cualquier disertación filosófica o jurídica sobre la necesidad de la justicia en la sociedad humana, ha sido el siglo pasado con la exterminación masiva de poblaciones y exclusiones económicas y sociales de semejante magnitud el que reclama que a la base de la práctica social democrática esté la observancia y búsqueda de la justicia. ${ }^{11}$

\section{La Solidaridad como presupuesto de toda verdadera sociedad}

La historia de la teoría y práctica de la solidaridad humana

Zelandia. Las tres últimas son Uzbekistán, Turkmenistán y Myanmar. Versión en caché de http://www.worldaudit.org/democracy. htm.Captura de pantalla de la página tal como esta se mostraba el 11 de Agosto de 2010 a las 16:28:03 GMT.

11. Baste con citar los datos más representativos: 1) 1.500 millones de personas viven sin electricidad. 2) 2 millones mueren cada año por causas relacionadas con la exposición al humo que se genera al cocinar con biomasa y carbón. 3) En la actualidad más de 1.000 millones de personas viven con menos de un dólar 
comparte la convicción de que toda persona supone el aporte de la sociedad que hizo posible su origen y desarrollo por lo que a todos nos corresponde aportar por el bien de toda la sociedad. "Hipoteca social" diría Juan Pablo II. De hecho es impensable una verdadera y saludable sociedad sin la mínima percepción por parte de sus integrantes de que a cada uno le corresponde contribuir al bien de la totalidad.

La solidaridad ha sido y puede ser objeto de utopías románticas; sin embargo, ello no ha de impedir que sea ella quien impulse toda iniciativa honesta para superar la escandalosa existencia de grandes masas humanas excluidas de los más fundamentales medios de subsistencia. La solidaridad es un valor que como tal ha de superar constantemente el estrecho cálculo economicista y el político autocrático. Ella ha de configurar desde la base la teoría y práctica de todo proyecto social.

\section{Un modelo político inclusivo y solidario a partir de Sanabria}

\section{El pluralismo inclusivo como condición necesaria}

Tanto Sanabria como el desarrollo teológico post conciliar

al día. 4) 1.800 millones de personas no tienen acceso al agua potable. 5) 2.000 millones de personas carecen de medicamentos esenciales. propugnan por el mayor desarrollo y respeto por un pluralismo fundado en la común dignidad humana. En el caso de Sanabria su convicción de que a la base de toda auténtica propuesta secular existen valores de extracción cristiana abre las posibilidades de modelos sociales inclusivos y solidarios.

\section{El diálogo como camino inevitable}

Desde la convicción de Sanabria sobre los valores comunes en todo humanismo integral y su práctica efectiva en la resolución de la cuestión social costarricense, el diálogo se presenta como el camino y la política insustituible e imprescindible para la construcción de toda sociedad democrática, inclusiva y solidaria.

\section{La justicia y la solidaridad como presupuestos indispensables e insustituibles}

Como patrimonio de la generación de los 40 Costa Rica posee verdaderas instituciones construidas sobre el valor de la justicia social y el solidarismo.

6) Más de 2 millones de personas mueren de hambre cada día, más que por la malaria, el sida y la tuberculosis juntos. Versión en caché de http://www.electrosector.com. Captura de pantalla de la página tal como esta se mostraba el 26 de noviembre de 2009. 
Para el primero consta el aporte de Sanabria y para el segundo el del también Benemérito de la Patria Don Alberto Martén ${ }^{12}$. Ambos tienen como gran presupuesto la democracia.

\section{Consideraciones finales}

\section{El presente papel del pasado para los proyectos de futuro}

Termino esta breve reseña de lo que la visión y obra de un gran humanista cristiano como Sanabria puede ofrecer para el presente y futuro de una teología y política de sociedad inclusiva y solidaria subrayando la importancia del primado histórico. Lamentablemente, la postmodernidad que vivimos padece de amnesia premeditada y ello abre el espacio para re-ediciones decadentes de mesianismos políticos y sociales desde diversos sectores. La factura la pagarán las mayorías vulnerables. En consenso con los grandes logros de la filosofía y teología del s.XX se debe insistir en el aporte imprescindible de una memoria histórica inclusiva. Esa memoria ofrece solidez y sostenibilidad a todo auténtico proyecto de sociedad justo y humano.

12. ROSALES (2010). La visión Filosófica de Don Alberto Martén. Padre del Solidarismo Costarricense. Heredia: UNA -por publicar-.

\section{La dimensión espiritual y} creyente como incentivo indispensable para la inclusión y solidaridad

Aún permanece viva la idea de que las religiones dividen. Sin aspirar a excluir a quienes así piensen se debe andar adelante para reconocer que aunque en el pasado eso pudo haber sido intencionadamente así, no debe ni tiene por qué seguir siéndolo cuando las religiones tienen un potencial privilegiado para cultivar la solidaridad y colaboración en pro del ser humano.

Sanabria ofrece un testimonio de cómo incluso la institución religiosa cuando se pone decididamente en favor de la resolución de los conflictos humanos en colaboración con las demás fuerzas sociales, puede ofrecer recursos ético-espirituales para trascender las rígidas barreras ideológicas con el fin de lograr resultados efectivos en la calidad de vida de la sociedad.

\section{El amor como definitivo poder realizador de toda utopía solidaria}

Al corazón de la espiritualidad, doctrina y praxis cristiana palpita el referente con el amor. Es la noción y experiencia que mejor manifiesta al Dios de los cristianos aunque no siempre estemos con nuestra vida a la altura de dicha referencia y aspiración. 
Sin embargo, si hay algo irrenunciable en el testimonio cristiano es apostar creativamente por el amor como invitaba Juan Pablo II (2001), como legado del Jubileo del año 2000, a la Iglesia del Tercer Milenio, ante las nuevas miserias y las atrevidas estrategias del amor para dignificar la vida humana en todas sus situaciones.

Así el pasado deja de ser un polo de nostalgia o escrúpulos culposos para convertirse en un sólido referente para la conversión sincera y la apuesta por la construcción de nuevos modelos de sociedad humana centradas en la dignidad de todo ser humano y el ambiente que lo nutre. América Latina ofrece un luminoso elenco de mártires por las causas sociales y solidarias y su testimonio sería incomprensible e incluso contradictorio si no lo valoráramos desde una opción radical por el amor fraterno a imagen de Jesús, el Testigo Fiel y Veraz. ${ }^{13}$

13. El diputado Trejos Dittel afirmaba en su intervención en la sesión de la Asamblea Legislativa del 19 de noviembre de 1959 con ocasión del benemeritazgo de Monseñor Sanabria: "Recuerdo que decía Monseñor Sanabria que lo que más influye en la virtud es el amor, porque el obstáculo fundamental de la vida moral es el egoísmo, y porque la más profunda aspiración de la vida moral es la liberación de sí misma. Recuerdo en que nos insistía en que sólo el amor, por ser donación de sí, es capaz de alejar este obstáculo y de llevar esta aspiración a la realización" (Blanco 1971: 358). Este es precisamente la

\section{Bibliografía}

AE SANABRIA cita de Archivos Eclesiásticos de San José, Arzobispado de Mons. Sanabria: años 1940-1942. Al citar esta fuente después de la abreviación sigue el número de caja, luego y entre paréntesis el número o título de fólder o documento y finalmente el número de folio consultado o la fecha que éste presenta. Vg. AE SANABRIA 45 (G) 15 de marzo de 1946. Esto significa caja 45, fólder $\mathrm{G}$ y documento fechado el 15 de marzo de 1946.

ANTÓN, A. (1987). El misterio de la Iglesia. Tomo II. Madrid: B.A.C.

AA. VV. (1948). Jacques Maritain. Paris: Ed. Desclée de Brouwer.

AA. VV. (1982). L'idea di un progetto storico. Dagli anni '30 agli anni '80. Roma: Ed. Studium.

BLANCO, R. (1971). Monseñor Sanabria. Apuntes biográficos. San José: Ed. Costa Rica.

ENSA. Cita de SOTO G.(1998). El Magisterio Pastoral de Monseñor Víctor Sanabria Martínez. San José: Ed. CECOR. Con su respectivo número de parágrafo en cada cita.

MARITAIN, J. (1980).Umanesimo integral. Roma: Ed. Borla.

ROSALES (2009). Los laicos en la visión de Iglesia Mons. Sanabria. Heredia: EUNA.

temática que desarrolla Maritain en su primer capítulo de Humanismo Integral y que intitula La tragedia del humanismo (MARITAIN 1980: 65-88). 
(2010). La visión Filosófica de Don Alberto Martén. Padre del Solidarismo Costarricense. Heredia: UNA -por publicar-.

SAN MARTÍN, N., La pareja del siglo, Jacques y Raïsa Maritain, en Actualidad Pastoral 254-255 (1999)42.

ULATE O., Corona fúnebre al Excmo. y Rvmo. Monseñor Dr. don Víctor Sanabria Martínez, en El Mensajero del Clero, julio de 1952, pp. 162-163.

\section{Sitios Web}

http://www.electrosector.com

http://www.worldaudit.org/democracy.htm 